\title{
25 Research Square \\ Epitaxial Growth and Optical Properties of Laser Deposited CdS Thin Films
}

Hamdan Ali Sultan Ali Sultan Al-shamiri ( $\sim$ h_elshamiri@hotmail.com )

Physics department- Faculty of applied science -Taiz university

Atef S. Gadalla

Cairo University

Huda F. Khalil

Centro de Ensenanza Tecnica y Superior Universidad Unidad Mexicali

Mahmoud M. El Nahas

Ain Shams University

Mohamed A. Khedr

Cairo University

\section{Research Article}

Keywords: Pulsed laser deposition, CdS thin films, Structure properties, optical properties, Photocurrent.

Posted Date: October 22nd, 2021

DOI: https://doi.org/10.21203/rs.3.rs-899271/v1

License: (c) (i) This work is licensed under a Creative Commons Attribution 4.0 International License. Read Full License 


\section{Abstract}

Cadmium Sulfide (Cds) thin films were synthesized on quartz substrates using infrared pulsed laser deposition (IR-PLD) technique under high vacuum ( $10^{-6}$ Torr). X-ray diffraction was used to evaluate the structural features. According to Xray analysis the deposited CdS films are crystalline and have a favored orientation on a plane (110) of an orthorhombic system and the peak intensity and the average crystallite size increases with increasing the film thickness. After annealing at $300^{\circ} \mathrm{C}$ the orthorhombic phase transformed into predominant hexagonal phase and the same result was obtained by SEM photographs. Spectrophotometric measurements of transmittance and reflectance of the Cds films were used to derive optical constants ( $n, k$ and absorption coefficient $a)$. The optical band gap energy was found to be $2.44 \mathrm{eV}$. The plasma plume formation and expansion during the film deposition have been discussed. The photocurrent response as a function of the incident photon energy $E(\mathrm{eV})$ at different bias voltages for different samples of thicknesses $(85,180,220$ and $340 \mathrm{~nm}$ ) have been studied, indicating that the photocurrent increases by increasing both the film thickness and photon energy with a peak in the vicinity of the band edge. Thus, the prepared Cds films are promising for application in optoelectronic field.

\section{Introduction}

Cadmium Sulfide CdS, is one of the composite semiconductors (II-VI). Which have a high direct energy gap (2.42 eV) at temperature (300 kelvin), where could be used in solar cells, light-emitting diodes, thin-film transistors, and optoelectronics devices. In light of this, Cadmium Sulfide (CdS) have attracted and attention of many researchers in the scientific and industrial filed. To produce a thin layer of Cadmium Sulfide (CdS), There are a variety of fabrication techniques used such as chemical bath deposition (CBD) [1, 2], electrodeposition [3], chemical spray pyrolysis (CSP) [4], successive ionic layer adsorption (SILA) [5], Spin-Coated [6 ],vacuum evaporation [7], screen printing [8], flash evaporation [9], sputtering [10], molecular beam epitaxy (MBE) [11], and pulsed laser deposition (PLD) [12,13]. Among these techniques, pulsed laser deposition (PLD), which have the following advantages (I) simple and easy: where a laser beam vaporizes a target surface, resulting in a film with the same composition as the target. (II) Many materials can be deposited in a variety of gases at a variety of pressures. (III) cost-effective: a single laser can power many vacuum systems. (VI) In 10 or 15 minutes, highquality samples may be reliably prepared. (IV) scalable. In general, easier to obtain the desired film stoichiometry for multielement materials using PLD than with other deposition technologies. In recent years, pulsed laser deposition (PLD) technique has been widely developed and become a suitable technique for the deposition of high-quality compound semiconductor thin films [14].

In this work, we will prepared thin films of Cadmium Sulfide CdS with different thickness by using pulsed laser deposition technique. where the laser ablation deposition system used for CdS thin films preparation consists of the evaporation source, which is the fundamental wavelength for Nd: YAG Laser (1064 nm), the evaporation process depends on laser parameters such as laser energies and pulses duration [15]. The deposition chamber: is made of stainless steel, finally pumping system: which is composed of a rotary mechanical pump connected with in series with a turbomolecular pump, This combination of the two pumps can reach a high vacuum pressure [16]. The film thickness can be controlled to a single atomic layer by fine adjusting the pulse number. Those unique merits make PLD suitable for the deposition of various highquality thin films [17]

The objective of the present work is synthesis of transparent and conductive CdS thin films with high quality, for optoelectronic devices applications.

\section{Experimental Details}

\subsection{Preparation CdS thin films}

Loading [MathJax]/jax/output/CommonHTML/fonts/TeX/fontdata.js 
Cadmium Sulfide (CdS) thin films were deposited in a vacuum chamber using $1064 \mathrm{~nm}$ Nd-YAG laser (Model PL-7010, CA 95051) produced by Continuum. Cadmium Sulfide (CdS) is a semiconducting compound (II-VI) in the powder form with purity of $99 \%(\mathrm{BDH})$. The CdS targets were made in the form of pellets with dimensions $10 \mathrm{~mm}$ in diameter and $3 \mathrm{~mm}$ in thickness by grinding the material to be homogeneous fine powder and then compressed under high pressure of $8 \times 10^{5}$ $\mathrm{N} / \mathrm{m}^{2}$. A CdS targets was mounted on a rotating target stage. The substrates were quartz glass placed $60 \mathrm{~mm}$ apart from the target surface. A schematic view of the film deposition setup is shown in Fig. (1).

Six samples of CdS thin film with different thickness were fabricated at room temperature. The vacuum chamber pressure was maintained $\sim 10^{-6}$ Torr during the entire deposition process. The laser Fluence was $4 \mathrm{~J} / \mathrm{cm}^{2}$ and repetition rate was 10 $\mathrm{Hz}$. The thickness of these six samples ranging from $60 \mathrm{~nm}$ to $340 \mathrm{~nm}$.

\subsection{Characterization techniques}

The film thickness was measured by the multiple beam Fizeau fringes method $[18,19]$. The X-ray diffraction patterns for $\mathrm{CdS}$ in the powdered and in thin film form for sample thickness $340 \mathrm{~nm}$ for as-deposited and after annealing at $300^{\circ} \mathrm{C}$ were recorded automatically using Philips, $\mathrm{Cu} \mathrm{K}$ radiation with $\lambda=1.54 \AA$. while the software Diano Corporation XSPEX (Woburn, Massachusetts 01801 U.S.A) and Fe filtered Co radiation with $\lambda=1.79 \AA$ were used for $X$-ray diffraction patterns and line broadening of (110) plane for different thicknesses of CdS thin films. The detector is scintillate counter with a dead time of less than $10^{-6} \mathrm{sec}$. The X-ray tube was energized at $45 \mathrm{kV}$ and $10 \mathrm{~mA}$.

Scanning electron microscope type Jeol 100S with $60 \mathrm{kV}$ operating voltage and a resolution of $50 \AA$ with zero angle of sample inclination, was used for study morphological surface of CdS films

Spectrophotometric method was used for measuring the optical transmittance $T$, and reflectance $R$ of CdS thin films in the spectral range of 200-2500 nm. UV/VIS/NIR double beam spectrophotometer (JASCO model V-570) was used.

Figure (1b) shows a schematic diagram of an operation circuit of photocurrent measurements for CdS thin films. White light from Xenon lamp (250 W) into a monochromator (Model 789A-3), goes through a chopper and collimating lens, into a thin film surface. Two indium electrodes are evaporated on the surface of the films and the distance between the two electrodes was $2 \mathrm{~mm}$.

External source $(0-7 \mathrm{~V})$ of applied voltage is used and the photocurrent response is detected by a double channel Lock-In amplifier (Model SR-530).

\section{Results And Discussion}

\subsection{Structural analysis}

The XRD patterns of the CdS powder and thin films deposited under vacuum (10-6 Tor) are shown in Fig. 2. for CdS in a powder form as represented in Fig. (1a) shows that there are two different phases (hexagonal and orthorhombic). The predominant phase is the hexagonal phase, as indicated from the peak intensities of the hexagonal one. The interplanar spacing $\left(\mathrm{d}_{\mathrm{hkl}}\right)$ were calculated using Diano Corporation XSPEX software and compared with those given in the (JCPDS) card file. Data representing the interplanar spacing $\left(\mathrm{d}_{\mathrm{hkl}}\right)$ and relative intensities l/lo for different (hkl) planes are given in Table (1). This indicates a polycrystalline nature of the powdered sample with lattice constants $a=4.136 \AA$ and $c=6.713 \AA$ for hexagonal form (ICDD 77-2306).

The X-ray pattern of the thin film shows a well-developed crystallographic texture (preferred orientation), where only two Loading [MathJax]/jax/output/CommonHTML/fonts/TeX/fontdata.js leir d values are related to the orthorhombic phase (ICDD 43- 
0985) which agrees with that reported by V.V.Yakovlev et al. [20]. This means that the crystallites of the film are oriented in such a way that the (110) planes are parallel to the substrate surface. The data representing the interplanar spacing $\left(d_{\text {hkl }}\right)$ are given in Table (1).

Table (1) X-ray data of CdS in the powder form, CdS thin film of thickness $340 \mathrm{~nm}$, CdS thin film of thickness $340 \mathrm{~nm}$ after annealing at $300^{\circ} \mathrm{C}$.

\begin{tabular}{|c|c|c|c|c|c|c|c|c|c|c|c|c|c|c|}
\hline \multicolumn{5}{|c|}{ CdS in the powder form. } & \multicolumn{5}{|c|}{ CdS thin film of thickness $340 \mathrm{~nm}$. } & \multicolumn{5}{|c|}{$\begin{array}{l}\text { CdS thin film of thickness } 340 \mathrm{~nm} \\
\text { after annealing at } 300 \mathrm{C} \text {. }\end{array}$} \\
\hline \multirow[t]{2}{*}{$\mathrm{d}_{\exp }$} & \multirow[t]{2}{*}{$\mathrm{I} / \mathrm{I}_{\mathrm{O}}$} & \multicolumn{3}{|c|}{ ICDD77-2306 } & \multirow[t]{2}{*}{$d_{\text {exp }}$} & \multirow[t]{2}{*}{$\mathrm{I} / \mathrm{I}_{\mathrm{O}}$} & \multicolumn{3}{|c|}{ ICDD 43-0985 } & \multirow[t]{2}{*}{$d_{\exp }$} & \multirow[t]{2}{*}{$\mathrm{I} / \mathrm{I}_{\mathrm{O}}$} & \multicolumn{3}{|c|}{ ICDD 77-2306 } \\
\hline & & $\mathrm{d} \AA$ & $\mathrm{I} / \mathrm{I}_{\mathrm{O}}$ & $\mathrm{hkl}$ & & & $\mathrm{d} \AA$ & $\mathrm{I} / \mathrm{I}_{\mathrm{O}}$ & hkl & & & $\mathrm{d} \AA$ & $\mathrm{I} / \mathrm{I}_{\mathrm{O}}$ & hkl \\
\hline 3.58 & 38 & 3.581 & 63 & 100 & 3.35 & 8 & 3.395 & 30 & 001 & 3.57 & 74 & 3.581 & 63 & 100 \\
\hline & & 3.356 & 45 & 002 & 2.81 & 100 & 2.812 & 80 & 110 & 3.36 & 100 & 3.356 & 45 & 002 \\
\hline 3.35 & 100 & 3.160 & 100 & 101 & 2.10 & 2 & 2.170 & 80 & 111 & 3.16 & 60 & 3.160 & 100 & 101 \\
\hline & & 2.449 & 25 & 102 & 1.41 & & 1.410 & 30 & 220 & 2.45 & 5 & 2.449 & 25 & 102 \\
\hline 3.16 & 48 & 2.068 & 43 & 110 & & 6 & & & & 2.06 & 77 & 2.068 & 43 & 110 \\
\hline & & 1.867 & 41 & 103 & & & & & & 1.89 & 13 & 1.867 & 41 & 103 \\
\hline 2.44 & 7 & 1.760 & 31 & 112 & & & & & & 1.76 & 18 & 1.760 & 31 & 112 \\
\hline & & 1.678 & 02 & 004 & & & & & & 1.25 & 5 & 1.257 & 79 & 105 \\
\hline 2.10 & 87 & 1.398 & 12 & 203 & & & & & & 1.19 & & 1.193 & 04 & 300 \\
\hline & & 1.303 & 04 & 114 & & & & & & 1.12 & 2 & 1.124 & 04 & 302 \\
\hline 1.90 & 20 & 1.257 & 79 & 105 & & & & & & & & & & \\
\hline 1.76 & 68 & $\begin{array}{l}1.193 \\
1.158\end{array}$ & 04 & $\begin{array}{l}300 \\
213\end{array}$ & & & & & & & 1 & & & \\
\hline & & 1.124 & 04 & 302 & & & & & & & & & & \\
\hline 1.68 & 6 & & & & & & & & & & & & & \\
\hline 1.39 & 4 & & & & & & & & & & & & & \\
\hline 1.30 & 4 & & & & & & & & & & & & & \\
\hline 1.26 & 2 & & & & & & & & & & & & & \\
\hline 1.19 & 11 & & & & & & & & & & & & & \\
\hline 1.15 & 3 & & & & & & & & & & & & & \\
\hline 1.2 & 7 & & & & & & & & & & & & & \\
\hline
\end{tabular}

Figure (2C) shows the X-ray diffractograms for patterns of CdS thin film of thickness (340 $\mathrm{nm})$ before and after annealing. When the sample was annealed at $300^{\circ} \mathrm{C}$ for two hours, X-ray pattern indicates that the intensity of the (110) plane was decreased and the (220) plane disappeared, and other peaks of the hexagonal form appear with considerable intensity as in Fig. (2b). This can be explained as that a part of the orthorhombic form is transformed into hexagonal one. The data in Table (1) show that the majority of the structure is hexagonal phase (ICDD 77-2306) with its characteristic peaks, and this is consistent with the SEM photographs of CdS as shown in Fig. $(5 a, b)$.

The resulting X-ray diffractograms for as-deposited CdS thin films with different thicknesses ranged from (60-340 nm) are represented in Fig.(3). All films showed preferred orientation parallel to [110] direction and the peak intensity increases with increasing film thickness where no shift in the peak position $\left(2 \theta=37^{\circ}\right)$ is observable

X-ray line broadening of the (110) reflection of the as-deposited CdS thin films with different thicknesses is represented in Fig. (3). The crystallite size and microstrain as a function of film thickness are determined and represented in Fig. (4: a, b) respectively. From Fig. (4a), it is observed that the average crystallite size increases with increasing the film thickness. The observation of A.Amith [21] and J.B.Wilson [22] regarding the increase of crystallite size with increasing of the film thickness agrees well with our results. Large number of $\mathrm{Cd}^{2+}$ and $\mathrm{S}^{2+}$ ions increase with increasing the film thickness and 
get adsorbed on the substrate and filling the voids leads to an increase in the value of crystallite size and the defects in the lattice are reduced which in turn reduces the microstrain [23] as shown in Fig. (4b).

Scanning electron microscope (SEM) micrographs represented in Fig. (5a, b) shows the orthorhombic form for the asdeposited CdS thin films.

\subsection{Optical Properties.}

The transmittance $(T)$ and the reflectance $(R)$ for each film were measured by spectrophotometric method at normal incidence of light in the spectral range $200-2500 \mathrm{~nm}$.

The spectral behavior of transmittance, $T(\lambda)$, and reflectance, $R(\lambda)$, for six different thicknesses of CdS films, are shown in Fig. (6) a, b. there are homogeneous CdS thin films in the thickness range (60-95 nm) Fig. (6)a, the others inhomogeneous films in the thickness range (180-340 nm), Fig. (6)b.

The transmittance for all CdS films decreases with increasing the thickness while increases with increasing wavelength.

The spectral behavior of refractive index $n(\lambda)$ and absorption index $k(\lambda)$ for the homogeneous CdS films represents Figure (7). The obtained results of both $n(\lambda)$ and $k(\lambda)$ show that these parameters are independent of the film thickness in the thickness range (60-340 nm). The fluctuation in both $n(\lambda)$ and $k(\lambda)$ can be attributed to the experimental errors in T, R and the film thickness (d). The curve behaves like a normal dispersion above $\lambda=1500 \mathrm{~nm}$ and shows anomalous dispersion towards a shorter wavelength. The peak that appears in the spectral distribution of the refractive index is due to a rapid increase in the absorption mechanism in the fundamental absorption edge [24]. No variations in (n) with the film thickness could be observed in the utilized film thickness ranges. The error in calculated values of (n) was estimated to be $3 \%$ due to experimental error for measuring $T, R= \pm 0.01 \%$, and film thickness $=2 \%$.

The absorption coefficient, (a) of as-deposited CdS thin films was calculated using the equation:

$\alpha(\lambda)=\frac{4 \pi k}{\lambda}$

Where $\mathrm{k}$; the mean value of the absorption index at a particular wavelength. The spectral behavior of the absorption coefficient (a) versus photon energy (hv) and the (ahu) ${ }^{2}$ as a function of hu for as-deposited CdS films are shown in Fig. (8). The optical transitions in semiconductors can be represented by

$\alpha h v=A\left(h v-E_{g}\right)^{m}$

Where $\mathrm{m}=0.5$ in case of allowed direct optical transitions [25]. The relation yields a straight line indicating allowed direct optical transitions where $\mathrm{Eg}=2.44 \mathrm{eV}$. To confirm the existence of the allowed direct optical transitions in CdS thin film, $\ln (\mathrm{a})$ is plotted as a function of $\ln (\mathrm{hu}-\mathrm{Eg})$ as shown in Fig. (9). One linear relation is obtained having a slope $=0.5$, indicating and confirming the allowed direct optical transitions.

\subsection{Plasma Plume and Spectral Profiles}

Plasma produced by the focusing of laser beam on solid targets became the object of intensive theoretical and experimental studies immediately after high power lasers became available [26].

Different diagnostic techniques, such as optical spectroscopy [27, 28], Laser-induced fluorescence [29], have been used in attempts to characterize the plasma as it expands either in a vacuum or in an ambient atmosphere. The laser beam is concentrated to a spot of $0.5 \mathrm{~mm}$ in diameter on the CdS target surface with an angle of incidence $0^{\circ}$. Expansions of the plasma plumes were observed and photographed by using a pinhole digital camera, when the Nd: YAG laser beam of

Loading [MathJax]/jax/output/CommonHTML/fonts/TeX/fontdata.js 
wavelength $1064 \mathrm{~nm}$ impinges onto a CdS target surface, the plasma expands perpendicularly to the target surface independently of the angle of incidence.

After a certain number of laser shots, the depth of the hole increases with the number of laser pulses. By rotating the target to get a new target surface, the direction of the plasma plume turns increasingly towards the incident laser beam, as shown in Fig. (10) a. By increasing the hole depth, the observed plasma plume outside the hole becomes shorter, and the intensity of the emission decreases, as indicated in Fig. (10) b, c. When the laser beam interacts with the plasma plume, some of its energy is absorbed by the atoms, exiting them. Electrons are pushed into high energy states, only to later fall back down to lower states. When this transition occurs, radiation is emitted at a specific frequency. The emitted spectra were recorded from a side window using a monochromator attached with a charge-coupled device (CCD) camera controlled by a computer program through an optical fiber. Spectra were taken at different distances from the target surface.

Figure (11)a-e shows the emission spectra from a CdS target. There is a broadening in the emission lines due to both frequent causes, namely the spectrometer having $0.5 \mathrm{~nm}$ resolution, and physical causes such as a "Doppler shift" due to atomic movement and the effect of atomic collisions in the target plume.

The image profile and three-dimensional profile of the spectral line $477.16 \mathrm{~nm}$ are shown in Fig. (11) a, b.

Unfortunately, most of the emission lines of the $\mathrm{Cd}^{2+}$ made up the plasmas lies in the ultraviolet region of the electromagnetic spectrum outside the range of our spectrometer but most of the $\mathrm{S}^{2+}$ lines are detected and were compared with the known emission lines [30] as represented in Table (2).

Table (2) Emission spectral lines of the plasma of the CdS target during the deposition:

\begin{tabular}{|l|lllll|}
\hline Obtained Spectral Data (nm) & 348.20 & $\mathbf{4 6 7 . 7 3}$ & $\mathbf{5 0 8 . 3 4}$ & $\mathbf{6 4 3 . 7 0}$ \\
\hline Reference Spectral Data (nm) [30] & 349.90 & 467.80 & 508.58 & 643.84 \\
\hline 3.4 Photoconductivity Response & & & &
\end{tabular}

The spectrum of the CdS thin films by a different bias voltage (1-6 V) was characterized with the photon energy, $E(e V)$, as shown in Fig. (12)a-d. The samples for each thickness 85, 180, 220 and $340 \mathrm{~nm}$, respectively, display increasing of the photocurrent response by raising the incident photon energy $\mathrm{E}(\mathrm{eV})$, with a peak in the vicinity of the band edge. This can be attributed to the generation of a greater number of free charge carriers in the bandgap region, and this is probably connected with the grain boundary, which induces an electric field due to the spatial distribution of electrons in the grain [31]. The optimized as-deposited CdS thin film at thickness $340 \mathrm{~nm}$ exhibits the high energy at voltage $6 \mathrm{~V}$ and photocurrent approximately 80 .

Figure (13) shows the voltage dependence of the dark current and photocurrent recorded for the as-deposited CdS thin film of $340 \mathrm{~nm}$. The dark current and the photocurrent increase straightly with the increase in the applied voltage in the region studied $(0-7 \mathrm{~V})$, and the photocurrent is greater than the dark current at the same bias voltage.

In darkness, the photoconductor resistance is very high, and when a voltage is applied, only a small dark current was observed. When light is incident on this photoconductor, a current (I) flows due to the generation of more number of charge carriers as illustrated in the figure below.

Here are the basic principles of the photoconductive effect [32]: (I) Directly beneath the conduction band of the CdS crystal is a donor level and there is an acceptor level above the valence band. In darkness, the electrons and holes in each level are almost crammed in place in the crystal and the photoconductor is at high resistance. (II) When light illuminates the CdS film surface and is absorbed, the electrons in the valence band are excited into the conduction band. This creates pairs of free

Loading [MathJax]/jax/output/CommonHTML/fonts/TeX/fontdata.js tion band, increasing the conductance. (III) Furthermore, near the 
valence band is a separate acceptor level that can capture free electrons only with difficulty but captures free holes easily. This lowers the recombination probability of the electrons and holes and increases the number of electrons in the conduction band for n-type conductance. Until the carriers generated in (II) and (III) recombine, electrons are injected from one electrode and pulled out by the other. When these carriers last longer and they move more, the conductance increases greatly.

\section{Conclusion}

The X-ray analysis of the prepared CdS thin films shows that all films crystalline with an orthorhombic system and have preferred orientation in (110) direction. The peak intensity of the plane (110) increases with increasing the film thickness. After annealing at $300^{\circ} \mathrm{C}$ for the sample of thickness $340 \mathrm{~nm}$, the X-ray diffraction pattern indicates that the orthorhombic phase is transformed into predominant hexagonal phase, and this was confirmed by SEM photographs. The average crystallite size of the films was growth with increasing film thickness due to the increase in the number of $\mathrm{Cd}^{2+}$ and $\mathrm{S}^{2+}$ ions with increasing the thickness, get adsorbed on the substrate and filling the voids. It increases crystallite size value, and the defects in the lattice are reduced, which reduces the microstrain in the samples. The cadmium Sulfide CdS follow the direct allowed transition with $E_{g}=2.44 \mathrm{eV}$. The direction of the plasma plume expansion is perpendicular to the target surface, and the plume length decreases with increasing the number of incident laser pulses. The photocurrent is increasing with expanding the film thickness, and this is often due to the growth of crystallinity of thin films with expanding the film thickness.

\section{References}

[1] Wilson K, Ahamed MB. Surface modification of cadmium sulfide thin film honeycomb nanostructures: Effect of in situ tin doping using chemical bath deposition. Appl surf sci 361 (2016): 277-282.

[2] Igor Perlikowski, Eunika Zielony, Teoman Özdal and Hamide Kavak. Structural Properties and Electrical Characteristics of p-n Junctions Based on Kesterite $\mathrm{Cu}_{2} \mathrm{ZnSnS}_{4}$ Layers for Thin-Film Solar Cells. Energies 14 (2021), 5182.

[3] Zhang Y, Ma H, Wu D, Li R, Wang X, Wang Y, Zhu W, Wei Q, Du B. A generalized in situ electrodeposition of Zn doped CdSbased photoelectrochemical strategy for the detection of two metal ions on the same sensing platform. Biosensors and Bioelectronics 77 (2016), 936.

[4] Yılmaz S, Atasoy Y, Tomakin M, Bacaksız E. Comparative studies of CdS, CdS: Al, CdS: Na and CdS:(Al-Na) thin films prepared by spray pyrolysis. Superlattices and Microstructures 88 (2015), 299.

[5] Kim W, Baek M, Yong K. Fabrication of $\mathrm{ZnO} / \mathrm{CdS}$, ZnO/CdO core/shell nanorod arrays and investigation of their ethanol gas sensing properties. Sensors and Actuators B: Chemical 223 (2016), 599-605.

[6] T. Özdal, T. Chtouki, H. Kavak, V. Figa, D. Guichaoua, H. Erguig, J. Mysliwiec, B. Sahraoui. Effect of Annealing Temperature on Morphology and Optoelectronics Properties of Spin-Coated CZTS Thin Films. Journal of Inorganic and Organometallic Polymers and Materials 31 (2021),89.

[7] Trajic J, Gilic M, Romcevic N, Romcevic M, Stanisic G, Hadzic B, Petrovic M, Yahia Y. Raman Spectroscopy of Optical Properties In CdS Thin Films. Science of Sintering 47 (2015), 145.

[8] Croitoru N, Jakobson S. Properties of CdS films and Cu 2 S-CdS junctions prepared by chemical printing. Thin Solid Films 56 (1979): L5-L7.

[9] Canevari V, Romeo N, Sberveglieri G, Azzi S, Tosi A, Curti M, Zanotti L. Low resistivity CdS thin films grown by flashG Loading [MathJax]/jax/output/CommonHTML/fonts/TeX/fontdata.js Journal of Vacuum Science \& Technology A, 2 (1984): 9-10. 
[10] Piel A, Murray H. Etude de la conduction Poole-Frenkel dissymétrique dans des structures Al-CdS-Au. Thin Solid Films 44 (1977) 65-73.

[11] Shay JL, Wagner S, Bettini M, Bachmann KJ, Buehler E. InP-CdS solar cells, IEEE Transactions on Electron Devices. 1977; 24: 483-486.

[12] Bleu, Y.; Bourquard, F.; Tite, T.; Loir, A.; Maddi, C.; Donnet, C.; Garrelie, F. Review of graphene growth from a solid carbon source by pulsed laser deposition (PLD). Front. Chem. 2018, 6, 572. [CrossRef] [PubMed]

[ 13] Elhmaidi, Z.O.; Abd-Lefdil, M.; El Khakani, M.A. Photoconversion Optimization of pulsed-laser-deposited p-CZTS/n-Sinanowires heterojunction-based photovoltaic devices. Nanomaterials 10 (2020), 1393

[14] Simon N. Ogugua, Odireleng Martin Ntwaeaborwa, and Hendrik C. Swart, Latest Development on Pulsed Laser Deposited Thin Films for Advanced Luminescence Applications, Coatings 2020, 10, 1078

[15] Hernandez-Como, N., Martinez-Landeros, V., Mejia I., Aguirre-Tostado, F.S., Nascimento, C.D., G. de M. Azevedo, C. Krug c , Quevedo-Lopez , M.A. 2014. " Defect control in room temperature deposited cadmium sulfide thin films by pulsed laser deposition," Thin Solid Films, 550: 665-668.

[16] J.H.Moore, C.C.Davis and M.A.Coplan, Building Scientific Apparatus: A practical Guide to Design and Construction, (Preseus Books) (1991

[17] R. Kossowsky, M. Jelinek, J. Novak, M. Jelínek, V. Trtík, L. Jastrabík, Pulsed laser deposition of thin films, in: R. Kossowsky, M. Jelinek, J. Novak (Eds.), Physics and Materials Science of High Temperature Superconductors, IV, Springer, Netherlands, 1997, pp. 215e231

[18] S. Tolansky,"Multiple-Beam Interference Microscopy of Metals", Academic Press, London (1970).

[19] S. Tolansky, "Multiple-Beam Interferometry of surface and films", Oxford University, London (1978).

[20] V.V.Yakovlev, V.Lazarov, J.Reynolds, and M.Gajdardziska-Josifovska, Laser-induced phase transformations in semiconductor quantum dots Appl. Phys. Lett., 76 (2000) 2050

[21] A.Amith, Thickness dependence of structural and electrical properties of Cds films for solar cells J. Vac. Sci. Technol., 15(2) (1978) 353.

[22] J.B.Wilson and J.Woods, The electrical properties of evaporated films of cadmium sulphideJ. Phys. Chem. Sol., 34 (1973) 171.

[23] T.Mahalingam, V.S.John, Microstructural characterization of electrosynthesized ZnTe thin films Cryst. Res. Technol., 37(2002) 329.

[24] A. F. Ioffe, " Physics of Semiconductor", 491 (London: Info search Limited) (1957).

[25] O.S.Heavens, "Optical Properties of Thin Solid Films" (London; England) (1955).

[26] T. Atwee and H-J.Kunze, Spectroscopic investigation of two equal colliding plasma plumes of boron nitride, J. Phys., 35 (2002) 524.

[27] T.Morrow, H.F.Sakeek, A.El-Astal and D.G.J.Walmsley, Absorption and emission spectra of the YBCO laser plume, J of Superconductivity and Novel Magnetism, 7 (1994) 823.

Loading [MathJax]/jax/output/CommonHTML/fonts/TeX/fontdata.js 
[28] X. T.Wang, B.Y.Man and X.Y.Hu, Optical spectroscopy of plasma produced by laser ablation of Ti alloy in air, J. Appl. Phys., 80 (1996) 1783.

[29 ] Christian Brackmann, Jenny Nygren' XiaoBai ZhongshanLi HenrikBladh Boman Axelsson' Ingemar Denbratt, Lucien Koopmans'Per-Erik Bengtsson MarcusAldén Laser-induced fluorescence of formaldehyde in combustion using third harmonic Nd:YAG laser excitation 59, (2003),33347

[30] Kramida, A., Ralchenko, Yu., Reader, J., and NIST ASD (2020NIST Atomic Spectra Database(Ver.5.8) [onlineSeptember [2021, Spectrmmeter] National institute of National] National Instituteof standards and technology Gaithrs DOI https://doi.org/10.18434/T4W30F.

[31] J. Dutta, D.Bhattacharyya, A.S.Chdhuri and A.K.Pal, Cadmium sulfide thickness effect on the photoresponse of the CdS(A1) spray/poly(3-methylthiophene) solid state junction, Solar Energy Materials and Solar Cells 29 (1993) 209.

[32] L. Heijne, Physical Principles of photoconductivity, Philips technical review 25, (1963) 120.

\section{Figures}

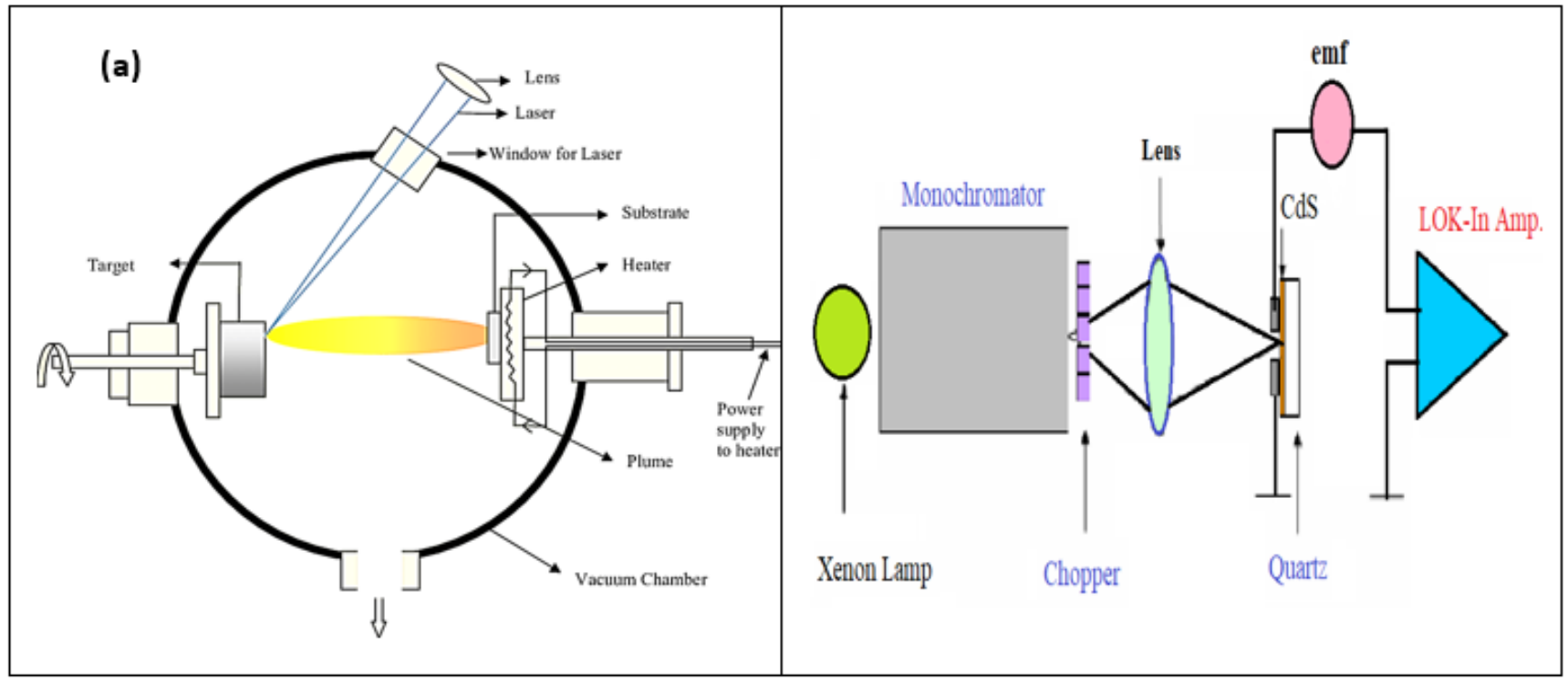

\section{Figure 1}

(a)The schematic diagram of pulsed laser deposition system. (b) Experimental setup for AC Photocurrent 

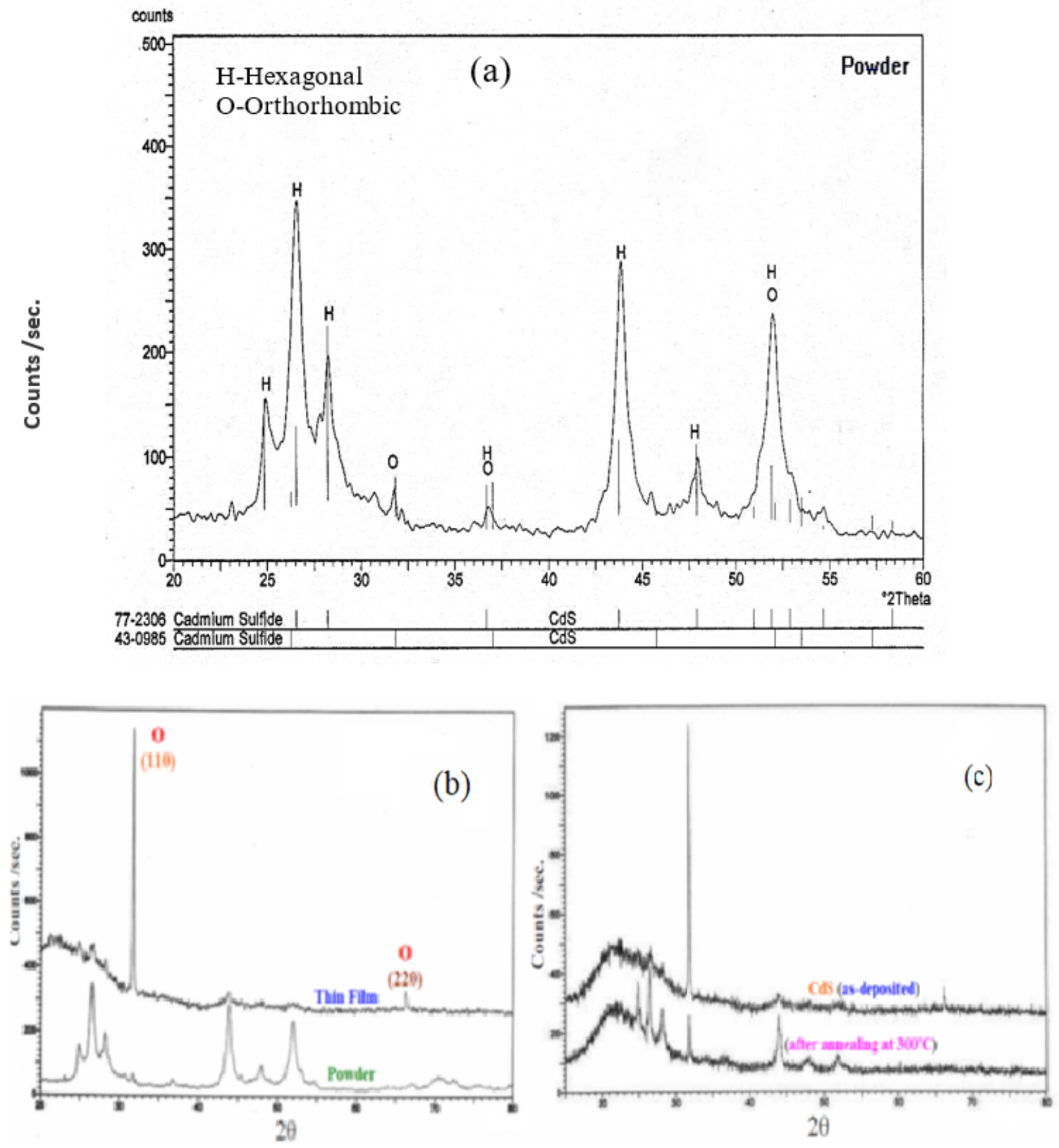

Figure 2

(a) Typical X-ray diffraction patterns as powder form. (b) In powder and thin film forms. (c) as- deposited and after annealing thin film at 300खC 


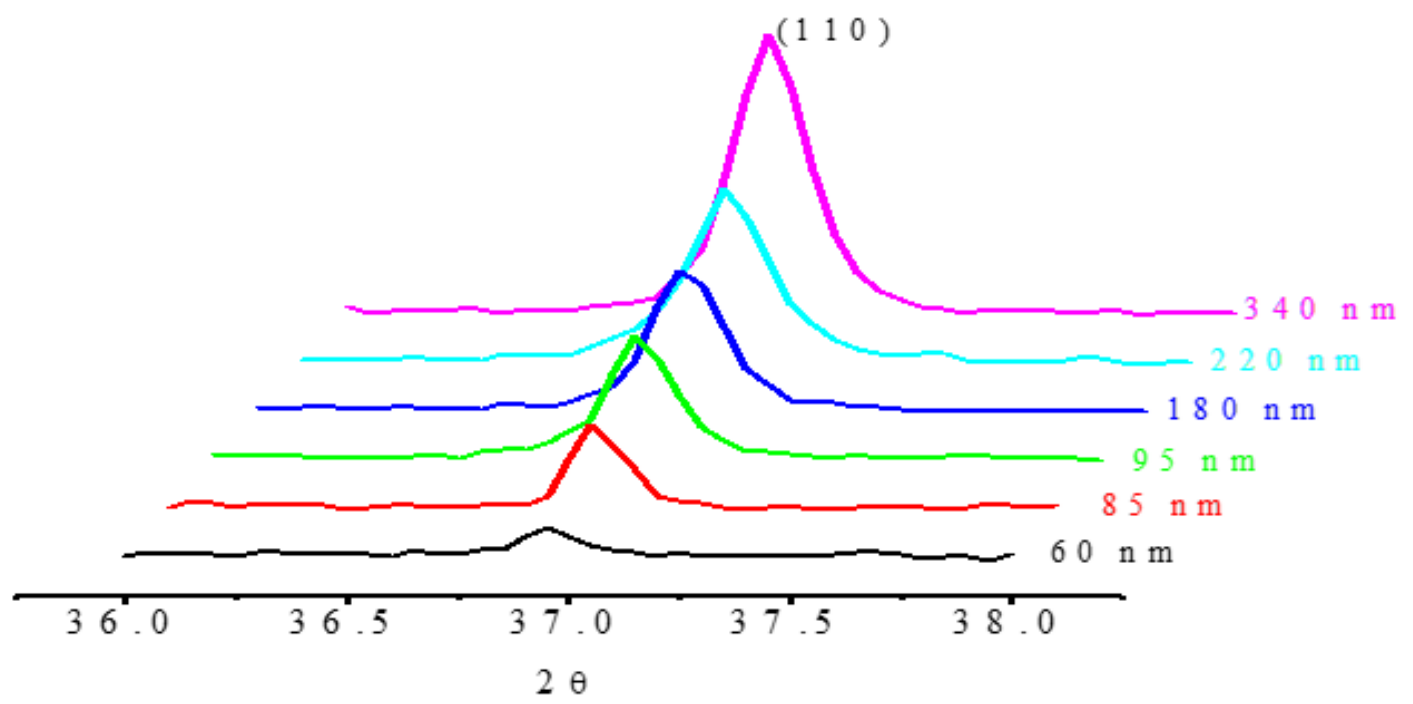

Figure 3

X-Ray of IR-PLD CdS thin films with different thicknesses.

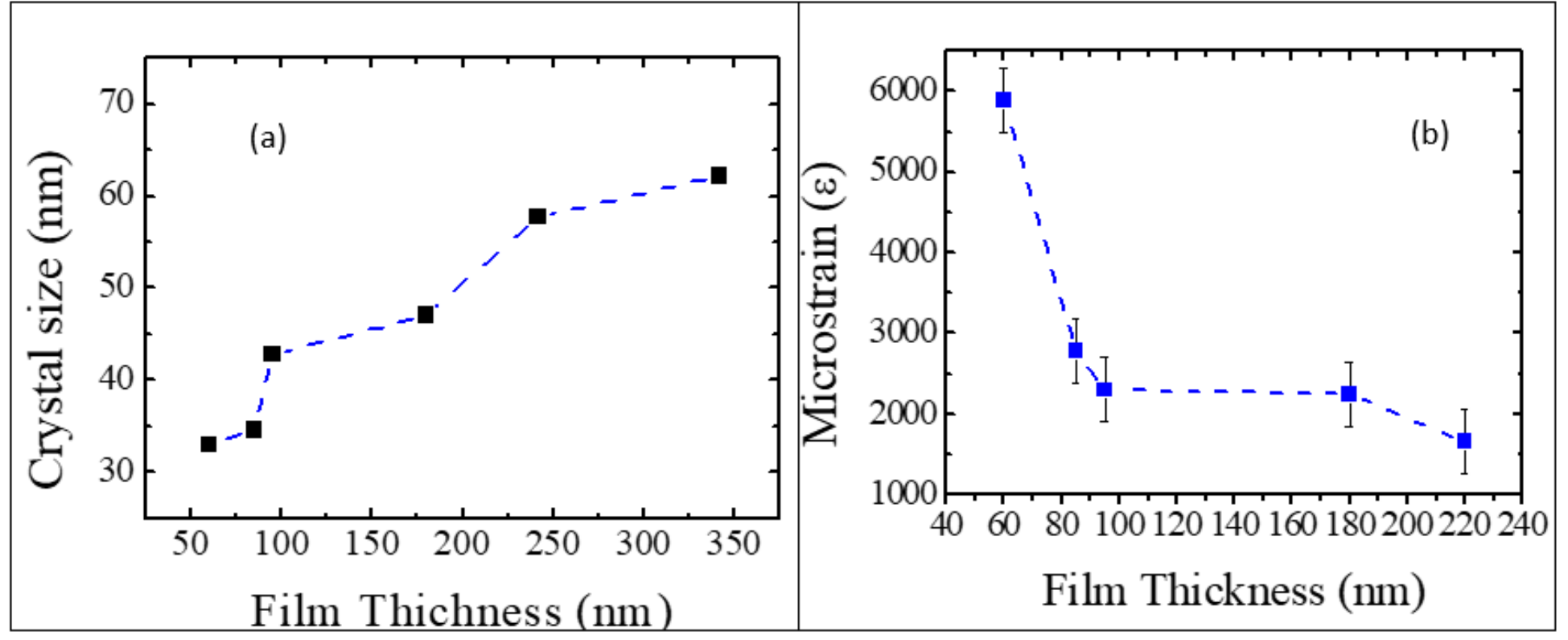

Figure 4

$(a, b)$ Crystal size, microstrain of CdS thin films as a function of film thickness. 


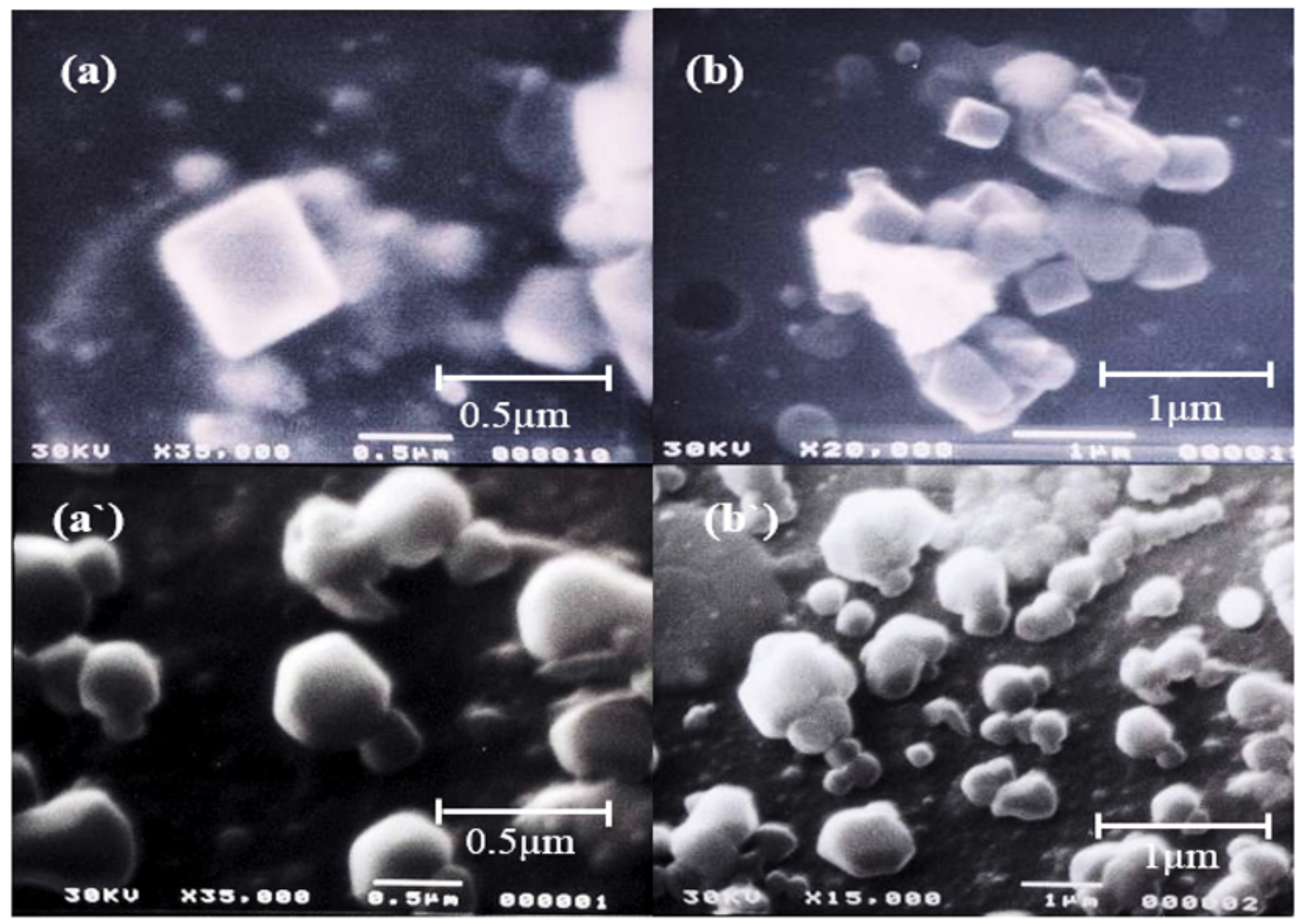

\section{Figure 5}

$(a, b)$ SEM micrographs of as-deposited IR-PLD CdS thin film, $(a, b)$ SEM micrographs of IR-PLD CdS thin film annealing at 300खC. 

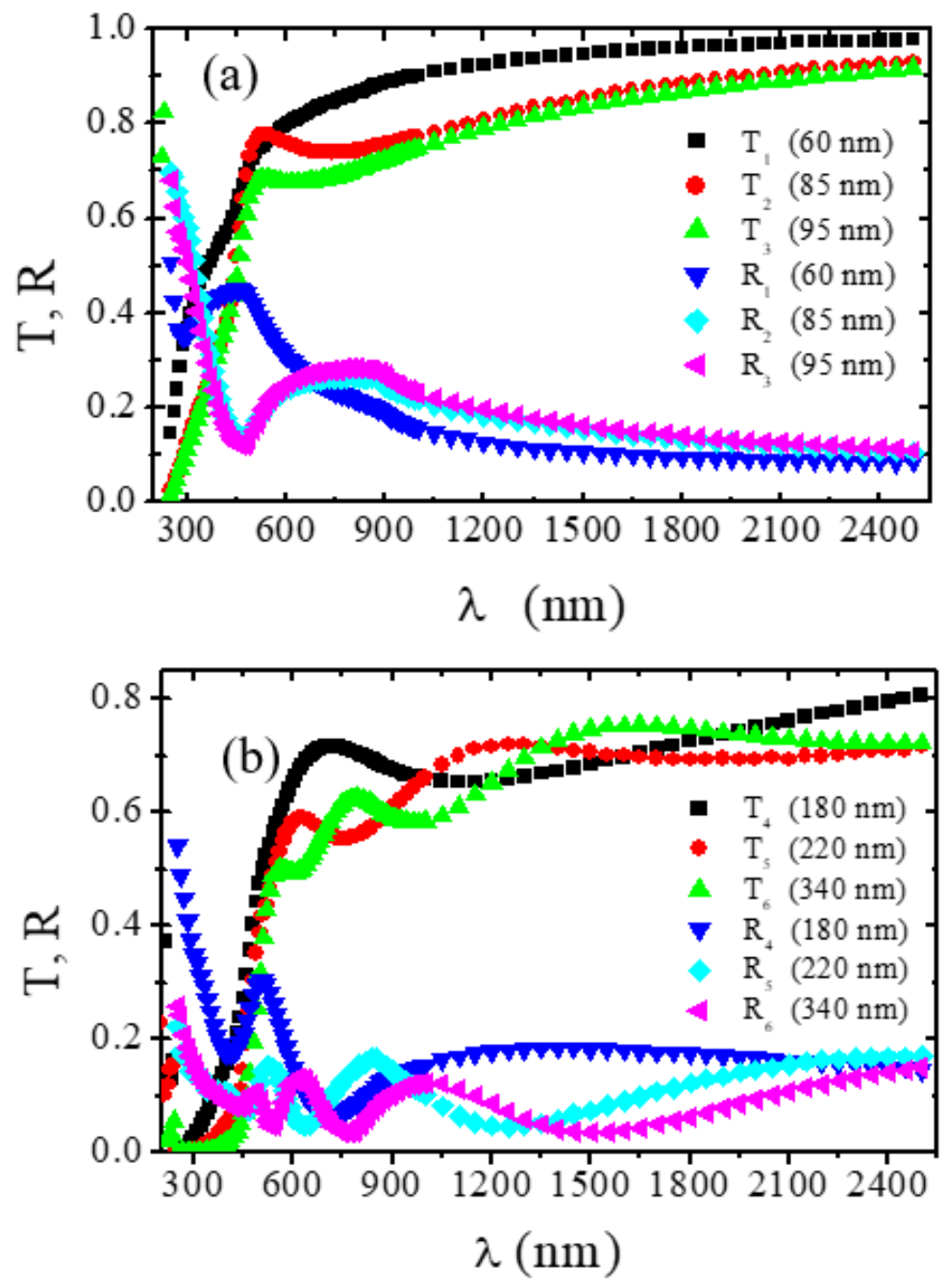

Figure 6

Transmittance and reflectance curves of (a) homogeneous CdS thin films (b) inhomogeneous CdS thin films.
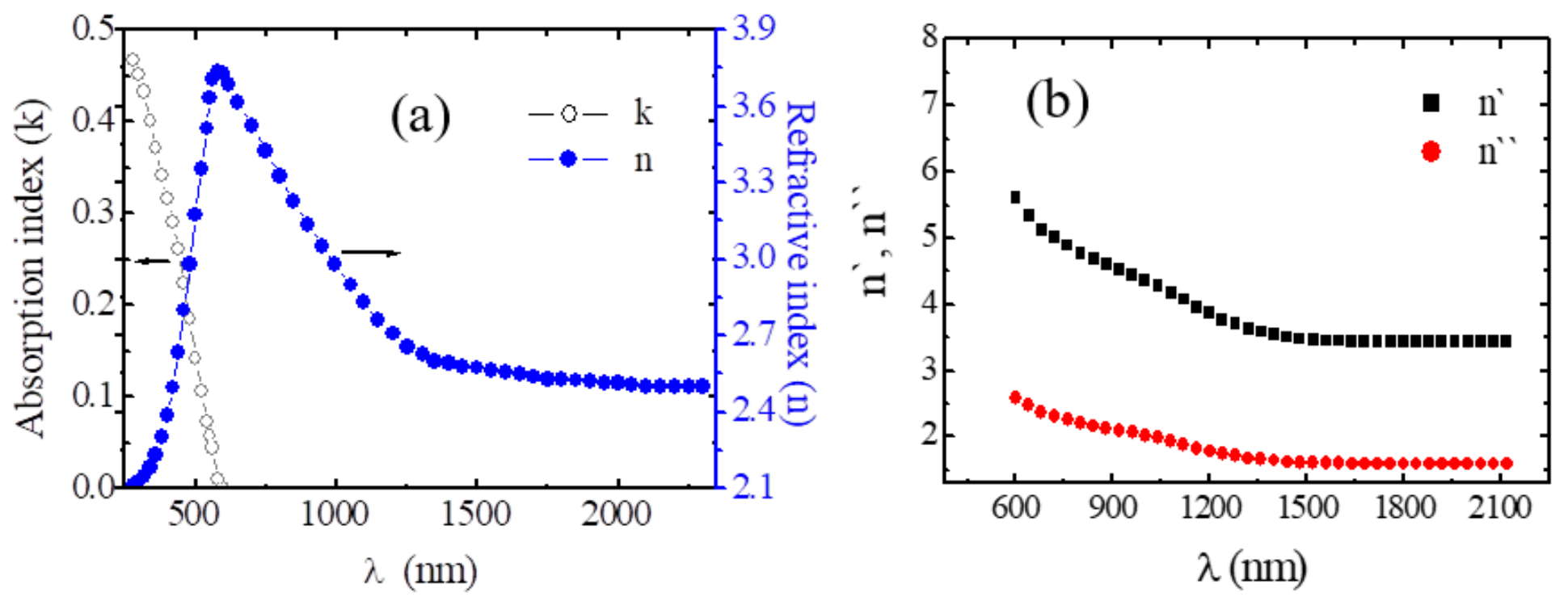

Figure 7 
(a) Refractive index (n) and absorption index (k) of CdS thin films at different wavelengths. (b) The dependence of refractive indices $n$ and $n$ ' of the wavelength for CdS films.

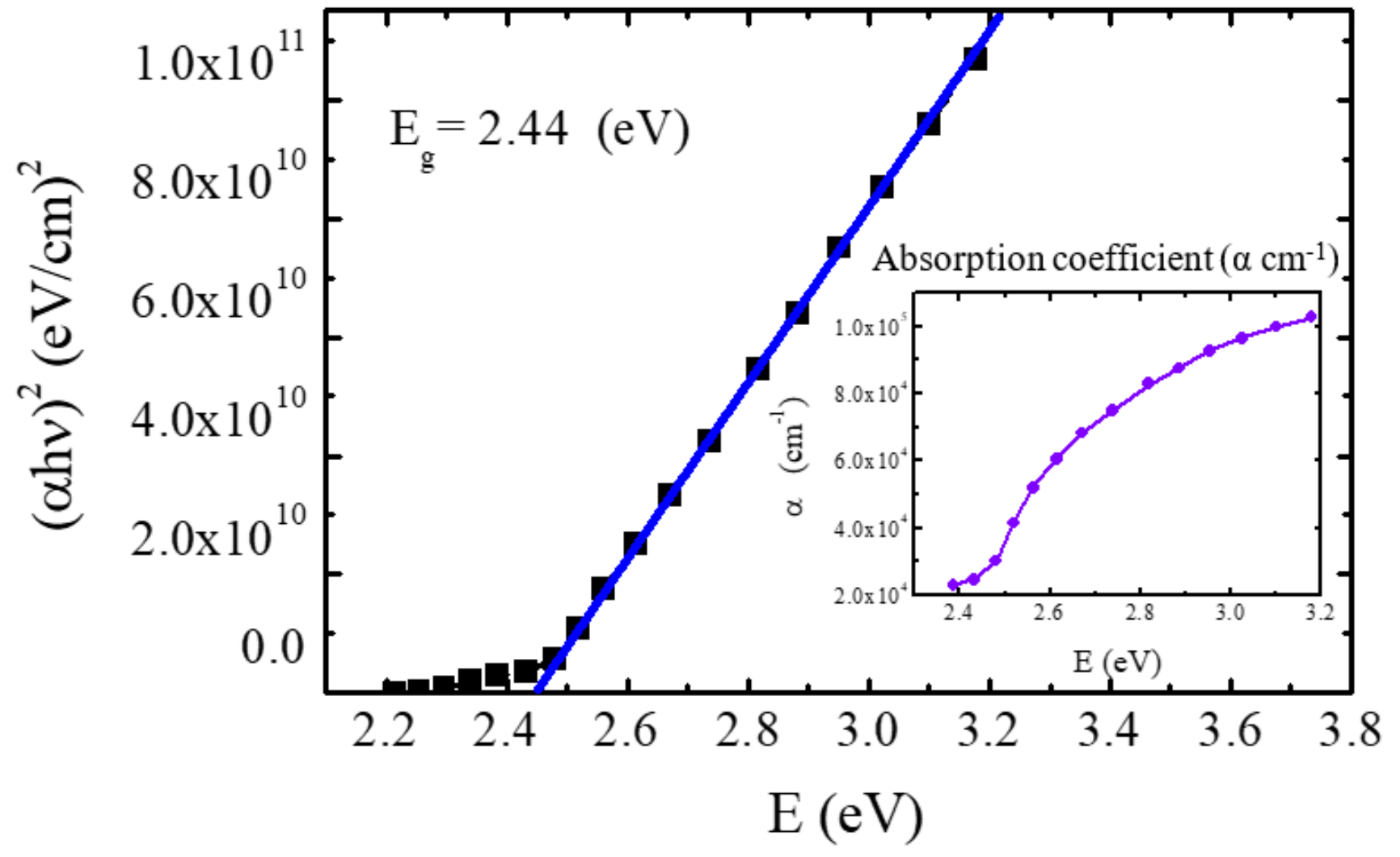

Figure 8

The relation between (ahv)2 and photon energy (hv) for CdS films.

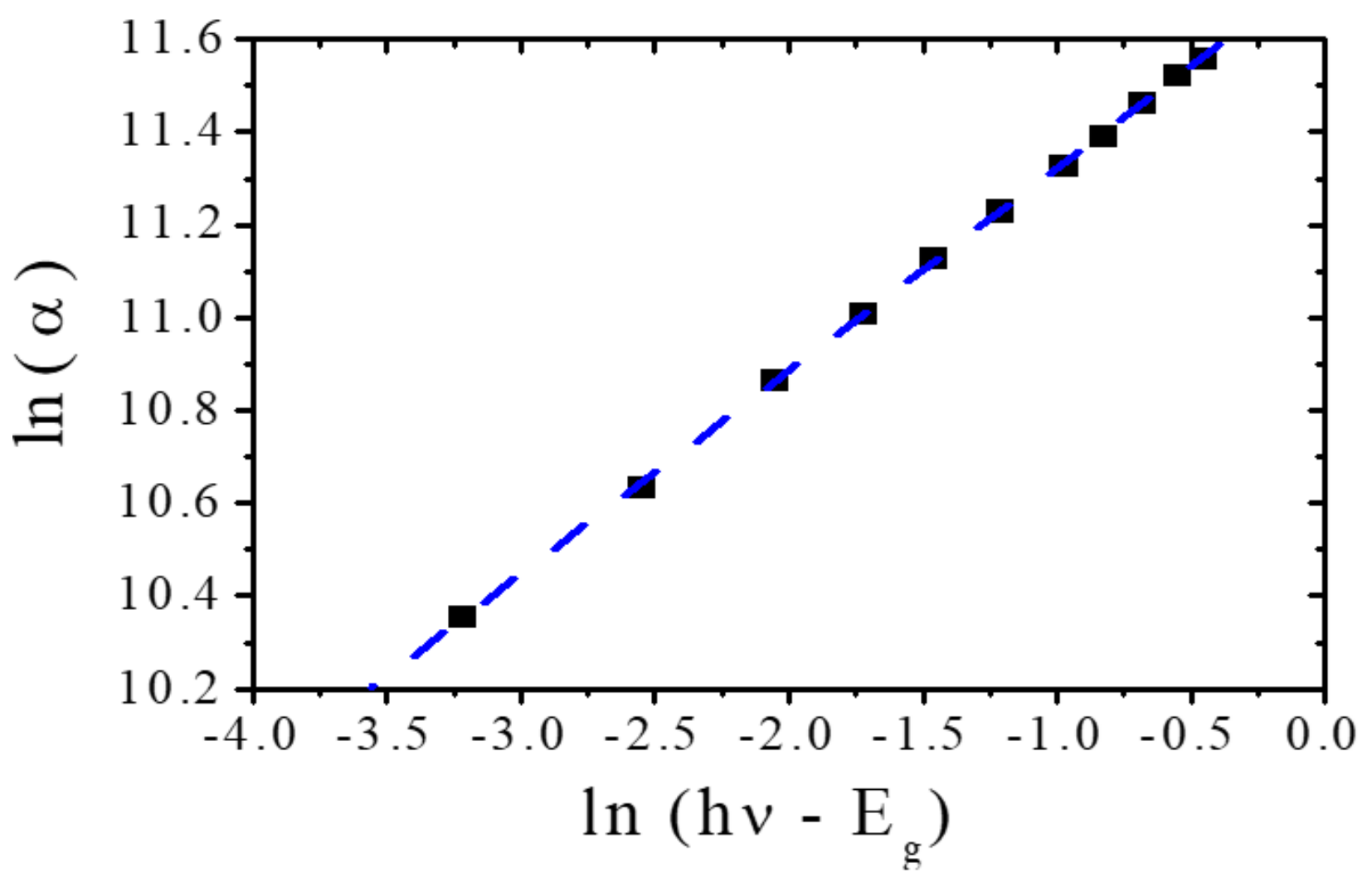



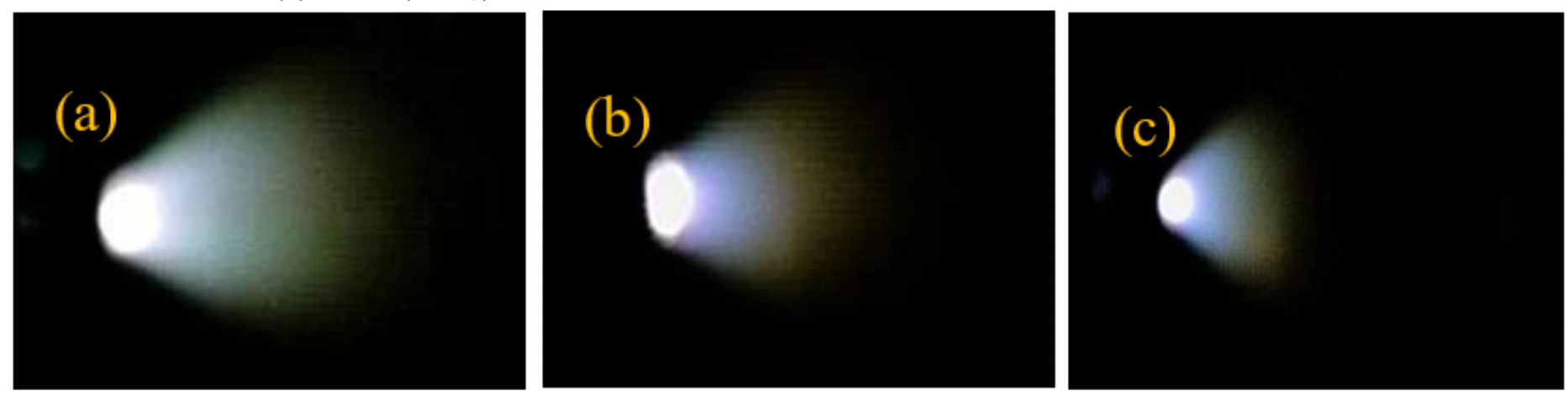

\section{Figure 10}

Time Integrated Pinhole images of the plasma plume during thin film deposition: (a) New target surface, (b) After 3000 laser shots, (c) After 6000 laser shots.

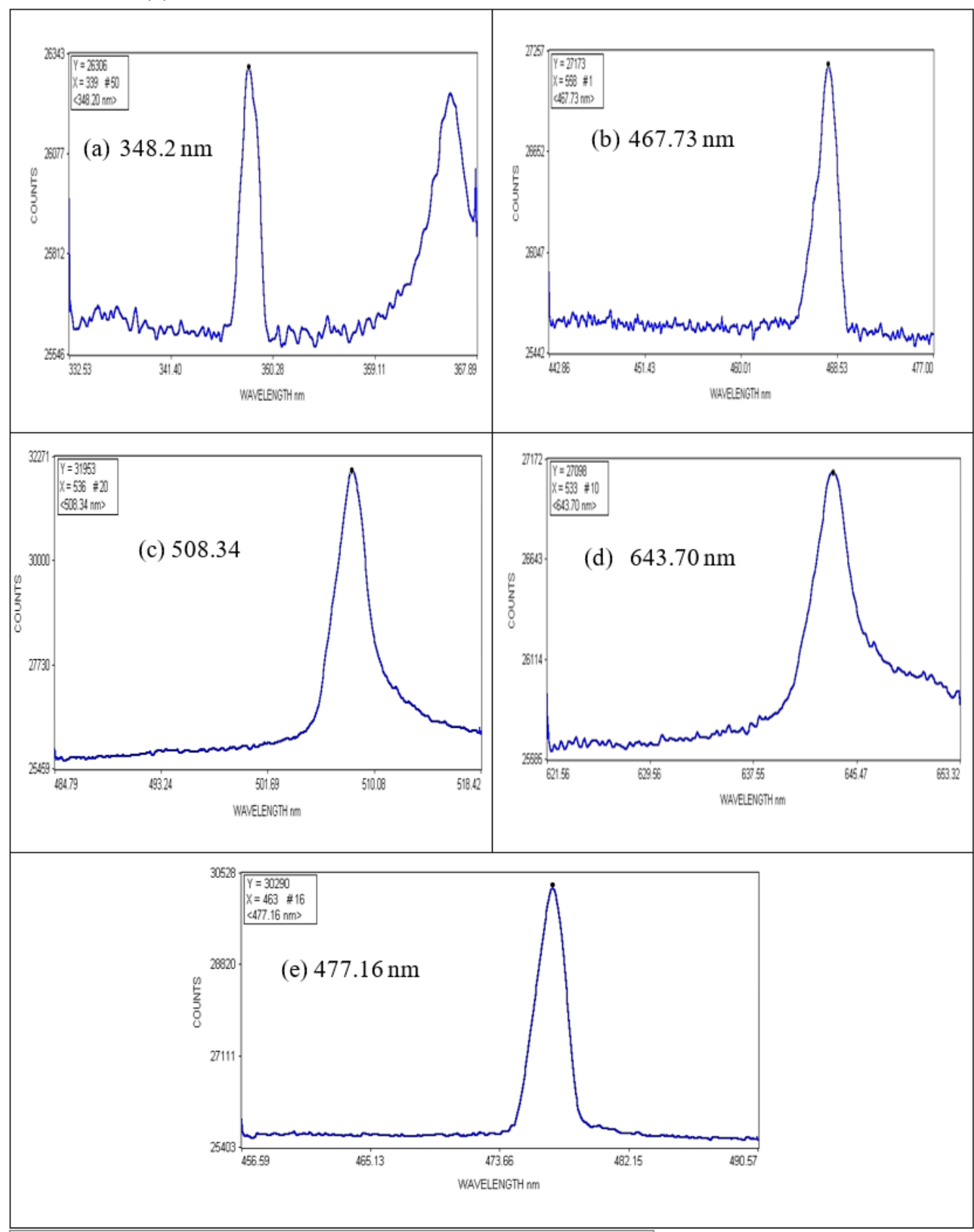




\section{Figure 11}

Plasma with different spectral line during the deposition.

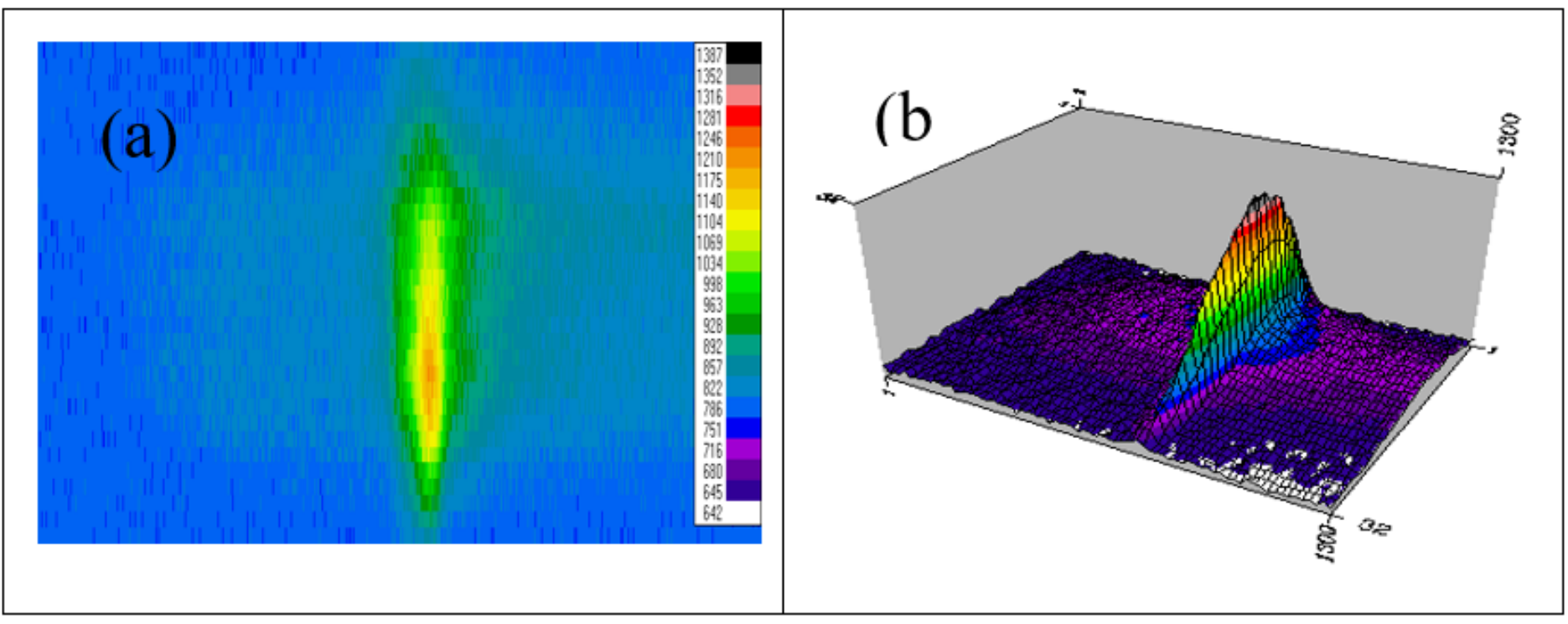

Figure 12

(a) Image profile of the spectral line $477.16 \mathrm{~nm}$, (b) Three-dimensional emission profile 


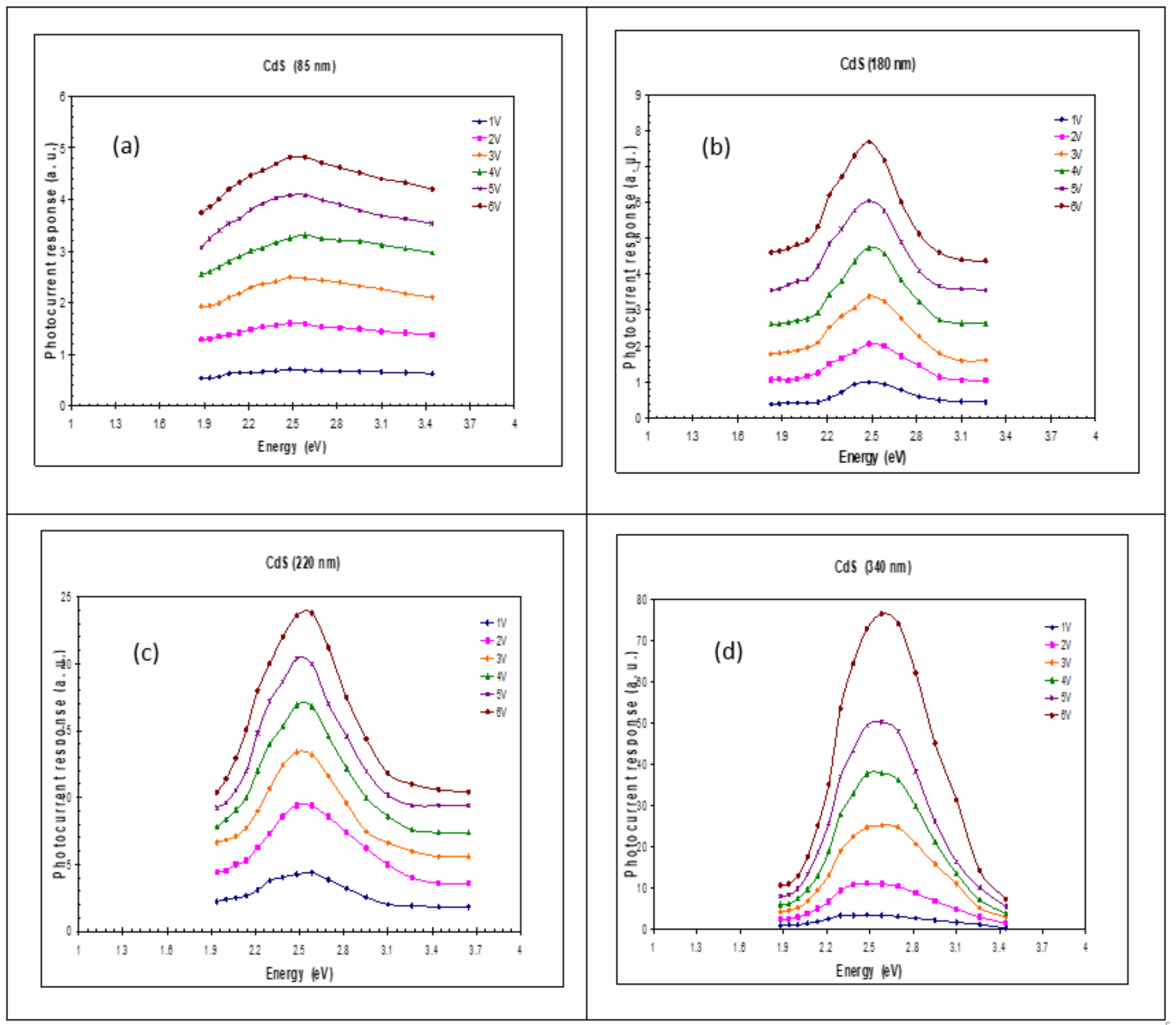

Figure 13

Photoconductivity response spectra at different bias voltage for CdS thin film with different thickness(a)85nm, (b)180nm, (c) $220 \mathrm{~nm},(\mathrm{~d}) 340 \mathrm{~nm}$. 


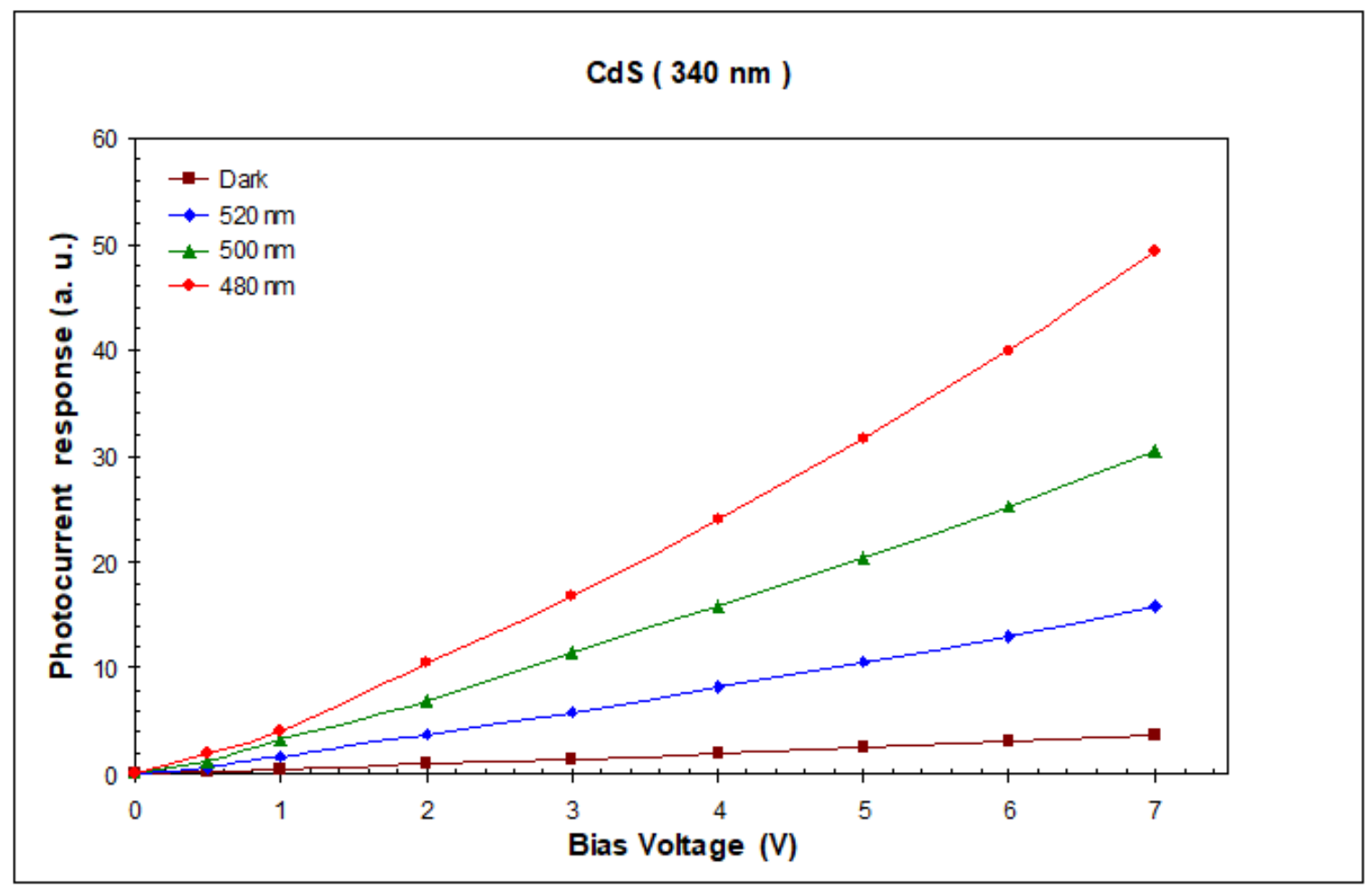

Figure 14

Dark and illuminated I-V characteristics at different wavelengths for CdS film with thickness $340 \mathrm{~nm}$.

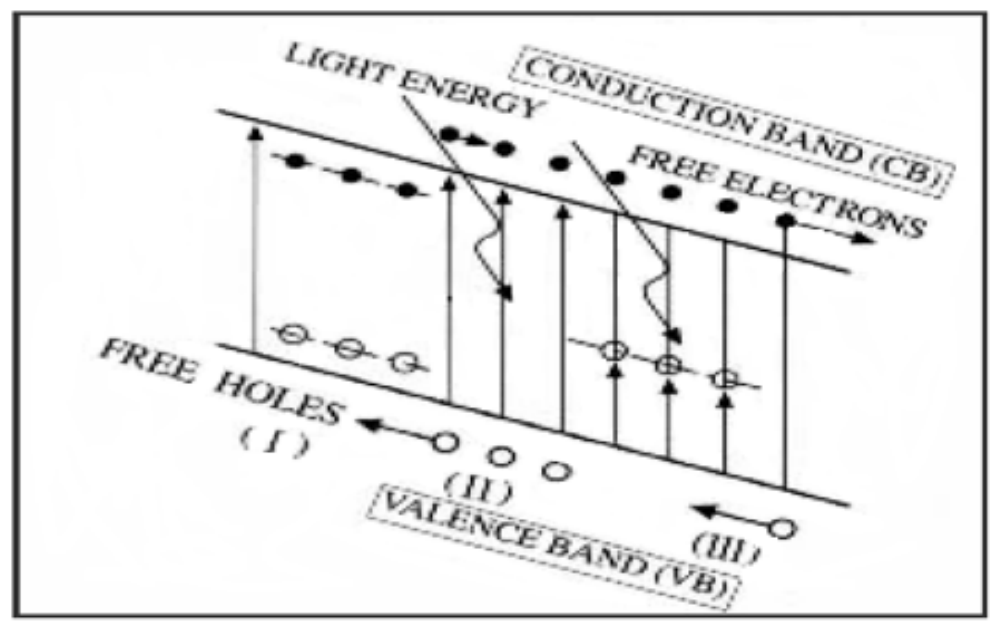

Figure 15

Carrier generation by light excitation 